\title{
Erratum to: Evidence of an age-related correlation of ovarian reserve and $F M R 1$ repeat number among women with "normal" CGG repeat status
}

\author{
Stephanie L. F. Gustin ${ }^{1} \cdot$ Victoria Y. Ding ${ }^{2} \cdot$ Manisha Desai $^{2} \cdot$ Benjamin Leader $^{3}$. \\ Valerie L. Baker ${ }^{1}$
}

Published online: 16 November 2015

(C) Springer Science+Business Media New York 2015

Erratum to: J Assist Reprod Genet (2015)

DOI 10.1007/s10815-015-0577-0

The authors would like to apologize for accidentally forgetting to include funding information. The following acknowledgement should have appeared: This research was supported by the NIH grant U54HD06815.

The online version of the original article can be found at http://dx.doi.org/ 10.1007/s10815-015-0577-0

\footnotetext{
Stephanie L. F. Gustin

sfisher@stanford.edu
}

1 Department of Obstetrics and Gynecology, Division of Reproductive Endocrinology and Infertility, Stanford University School of Medicine, 900 Welch Road, Suite 20, Palo Alto, CA 94034, USA

2 Quantitative Sciences Unit, Center for Biomedical Informatics Research, Stanford University School of Medicine, 1070 Arastradero Road, Palo Alto, CA 94304, USA

3 Clinical Research Division, ReproSource, Inc, 300 Tradecenter, Suite 6540, Woburn, MA 01801, USA 